\title{
BALANCE POSTURAL ASSESSMENTS AND FUNCTIONAL MOBILITY IN SUBJECTS WITH KNEE OSTEOARTHRITIS
}

\author{
Ana Carolina Silva De Souza Moreira', Gilmar Moraes Santos²
}

\begin{abstract}
INTRODUCTION: Knee Osteoarthritis (KOA) affects joint cartilage causing pain, musculoskeletal and proprioceptive disorder that may favor the occurrence of postural balance disorders during activities of daily living. OBJECTIVE: To analyze the clinical variables, the balance profile and the functional mobility of subjects with KOA with and without a history of falls. METHODS: Sixty-four women, 50 to 75 years of age, were separated into three different groups: KOAF group (18 subjects with KOA and previous history of falls); KOANF ( 24 subjects with KOA and no previous history of falls) and control group - CG ( 22 healthy subjects). The Womac questionnaire was used to analyze functional disability. For the functional evaluation of the balance, two instruments were used, the Berg's Balance Scale (BBS) and the Timed Up and Go test (TUG). For static balance evaluation, was used the stabilization diffusion analysis method (SDA) and analysis of the balance stabilizer of center of pressure (COP). RESULTS: It was evidenced that the BBS and WOMAC Scores were significantly lower for the KOA group. The functional evaluation of the balance showed that the TUG test time and BBS score were significantly lower in subjects with KOA than in CG. The KOA groups (KOAF and KOANF) presented a greater displacement of the $\mathrm{COP}$, anterior-posterior (AP) direction, and ellipse area than CG, in the closed-eyes condition. The KOAF group showed higher average speed of COP than CG. In the analysis of stabilogram diffusion, for both visual conditions, the KOA groups presented higher values in the short-term interval, long-term interval and critical point position than CG in the AP direction. CONCLUSION: The results imply that subjects with KOA, regardless of the previous history of falls, show a deficit of balance, increasing the risk of falls in this population.
\end{abstract}

Keywords: Postural Balance. Accidents by Falls. Knee Osteoarthritis.

\section{INTRODUCTION}

Currently osteoarthritis $(\mathrm{OA})$ is the chronic-degenerative disease that most affects the elderly. The knee is especially affected, between $23 \%$ and $40 \%$ of this population ${ }^{(1)}$. The progress of this disease causes deficits of the proprioceptive, neuromuscular and joint instability systems ${ }^{(2)}$, subjecting subjects to pain, limitation of movement, muscle weakness and decrease in coordination ${ }^{(2,3)}$. Thus compromising the postural balance due to a decrease in the ability of precision, agility and automatism to perform body movements ${ }^{(4)}$. Previous studies $^{(4,5)}$, associated increased postural instability and worsening functional capacity with increased risk of falls. In this context, the presence of knee osteoarthritis (KOA) could accelerate the deterioration of the balance control system associated with changes in the aging process itself ${ }^{(3)}$.

Widely used for balance assessment, the center of pressure (COP) analysis indicates the displacement of the trajectory of the vector of the ground reaction force. Traditionally posturography uses the displacement, velocity and ellipse area analysis of the COP. However, this may offer insufficient sensitivity to detect postural balance deficit, since the displacement of COP in the orthostatic posture does not behave as a stationary phenomenon ${ }^{(6)}$. Collins and De Luca characterized the behavior of the dynamic COP in a time series and reported inconsistencies in the stochastic nature of the COP which may be a variety of mechanisms of the processed signal or a static characteristic in a time series, referred to as stabilogram diffusion analysis (SDA $)^{(6)}$. This method has shown sensitivity for manipulations of variables related to postural balance, including age, vision, muscle torque and proprioception.

To date no study has been found based on this method of analysis of COP in KOA patients. In addition, there is a shortage of studies associating physiological changes and clinical conditions (degree of joint cartilage degeneration caused by $K O A$, pain, functional capacity) to its influence on balance. In view of these considerations, this study aimed to analyze the COP behavior by SDA among patients with KOA, with and without history of fall.

Corresponding Author: Ana Carolina Silva De Souza Moreira. Universidade do Estado de Santa Catarina (UDESC), Centro da Ciência da Saúde e do Esporte/CEFID. Address: Rua Pascoal Simone, n 358, Coqueiros, Florianópolis, SC, Brazil. CEP: 88080-350. Phone: 005548984113345 / 005548 30946173. E-mail: anakarolfisio@gmail.com

${ }^{1}$ Post-graduation Program of Science of Human Movement, Universidade do Estado de Santa Catarina - UDESC, Florianópolis (SC), Brazil 


\section{METHODS}

This study was descriptive cross-sectional with non-probabilistic sampling by trial. It was approved by the Ethics Committee of the Universidade do Estado de Santa Catarina, protocol $n^{\circ} 068 / 2008$, according with the resolution 196/96 of the National Health Council. All study participants signed the informed consent form. Sixty-four women from 50 to 75 years old were selected, referred by the Orthopedics outpatient clinic of the University Hospital of the Universidade Federal de Santa Catarina and by the Physiotherapy clinic of the Universidade do Estado de Santa Catarina. They were divided in three groups: Knee Osteoarthritis Group with Fall History (KOAF), with 20 subjects; Knee Osteoarthritis Group with No Fall History (KOANF), with 20 subjects; and the control group (CG), with 22 subjects.

For groups with osteoarthritis, were selected bilateral idiopathic KOA patients capable of walking for at least 6 meters without assistance. The diagnosis was confirmed by a specialist in orthopedics and traumatology, using the criteria of the "Colégio Americano de Reumatologia" and by bilateral radiographic examination of the knees, carried out within a maximum period of 6 months. The degree of alteration of the tibiofemoral joint surface was classified by the grading system for osteoarthritis of Kellgren - Lawrence, adopted officially by the World Health Organization (WHO). For CG, the participants should be independent wandering and without signs and / or symptoms of knee osteoarthritis, through clinical examination and X-ray.

The following subjects were excluded: history of lower limb and/or spine surgery in the last 12 months; musculoskeletal disorders that would prevent maintenance of the orthostatic position for the time determined in the study (approximately 30 minutes); be a user of body weight support device for ambulation (such as walking stick, crutch, walker); subjects with diabetes mellitus type I or II; history of previous treatment for improvement of balance, neurological disorders in the physical therapy evaluation and / or clinical diagnosis report; and disturbances in the vestibular and cerebellar system - evaluated by clinical neurological tests.

Were used in the study the following tools: VAS - Visual Analogue Scale, the WOMAC - Western Ontario and McMaster Universities, Mini Exam of the Mental State- MEEM, the Berg Balance Scale, Timed get up and go test (TUG), Chattecx Balance System Kim-Com ${ }^{\circledR}$ and the Stabilogram Diffusion Analysis.

\section{VAS - Visual Analogue Scale}

To verify the intensity of the pain, the numerical visual analog scale (VAS) with $10 \mathrm{~cm}$ of horizontal length, ranging from $0 \mathrm{~cm}$ (without pain), was used every $1 \mathrm{~cm}$ according to the degree of worsening of the pain sensation up to $10 \mathrm{~cm}$, considering the maximum value of worsening pain.

\section{WOMAC - Western Ontario and McMaster Universities}

WOMAC is a functional capacity questionnaire of the knee joint that comprises 24 questions, 5 assess pain, 2 assess oint stiffness and 17 assess physical activity, all of which are specific for the evaluation of subjects with knee osteoarthritis. Its maximum score is 96 points and each question has four alternatives ranging from 0 (extreme) to 4 points (none). The results were described in values ranging from 0 (worst condition) to 96 (better condition).

\section{Mini Exam of the Mental State- MEEM}

MEEM is an instrument used for initial mental status screening, which evaluates the presence of cognitive deficit, involving two categories of verbal and nonverbal responses. The MEEM is composed of 30 categorical questions, ranging from 0 to 30 points. The test scores classify the cognitive deficit in: 30 to 26 , the subjects has preserved cognitive functions; from 26 to 24 , there is a non-suggestive deficit; 23 points or less, suggestion of cognitive deficit. Verbal subtests measure, in particular, spatio-temporal orientation, immediate memory, recall and memory of procedure, attention and language. Non-verbal subtests measure perceptual-motor coordination and comprehension of instructions.

\section{Berg Balance Scale}

The Berg Balance Scale (BBS), validated by Miyamoto et al. (2004), was used to ascertain the dynamic and static balance of the elderly and the risk of falls considering the environmental influence on the function. BBS evaluates the performance of the functional balance with 14 tests, the individual's ability to sit, stand, reach, rotate around himself, look over his shoulders, stand on unipodal support, and transpose steps. Each test has five alternatives ranging from 0 to 4 points with a maximum score of 56 points. The points are based on the time at which each position can be maintained at the distance at which the upper limb is able to reach the front of the body and in time to complete a task.

\section{Timed get up and go test (TUG)}

The TUG test assess the mobility and balance of subjects. The test quantifies in seconds the functional mobility through the time the individual performs the task, that is, in how many seconds does she lift from a standard chair with backrest and arms and approximately $42 \mathrm{~cm}$ in height and arms of $62 \mathrm{~cm}$ in height, walks 3 meters, turns, returns to the chair and sits again, straight. The test evaluates the risk of falling considering the execution time.

\section{Chattecx Balance System Kim-Com ${ }^{\circledR}$}

In order to evaluate the variables of the anteroposterior and mid-lateral COP, was used the Chattecx Balance System Kim-Com ${ }^{\circledR}$ da Chattanooga Group. The equipment has a 
predetermined frequency of $100 \mathrm{~Hz}$ and filtering of $15 \mathrm{~Hz}$, the analog signals of the transducers being amplified and converted into digital signals by the system software itself.

\section{Stabilogram Diffusion Analysis}

Collins and De Luca(6) report that this method of analysis describes the evolutionary properties of the fractal and the time of the COP and presupposes additional information about the nature of the postural control system. The COP diffusion stability curve shows one region after a short time interval and another after a long time interval. These are separated by a critical period, after which the slope of the chart undergoes considerable changes. The posturographic parameters that are extracted from these regions:

- Diffusion Coefficient: The diffusion stabilogram allows the identification of this parameter in two regions of the graph, in a short time interval (DST) and in a long time interval (DLT). These regions seem to imply in the existence of a control scheme that consists of an open-loop mechanism and a close-loop mechanism to maintain postural equilibrium ${ }^{(6)}$.

- Exponent of Hurst: Evaluates the probability of COP to move far or near a relative equilibrium point, obtained through the slope of the linear regression of the diffusion stabilogram graph, with values between $0.5<\mathrm{H}<1$ would be associated with persistent behavior. The Hurst exponents with values smaller than 0.5 would be tending to return to a relative equilibrium point ${ }^{(6)}$.

- Critical point $(\Delta \times 2)$ : It represents the position that occurred the separation of the two regions (short and long time interval) in the diffusion stabilogram ${ }^{(6)}$.

- Critical point instant $\left(\Delta r^{2} c\right)$ : Refers to the moment (instant) that occurred the point of intersection of the two regions (short and long time interval) in the diffusion stabilogram ${ }^{(6)}$.

\section{Procedures}

Initially, the participants were referred to the Laboratory of Biomechanics of Universidade do Estado de Santa Catarina, where they provided information on: age, race, marital status and knee pain intensity on the day of collection (VAS scale).

Considering that, this study had an observational character of the phenomenon, with the purpose of portraying postural balance and functional mobility as close as possible to the reality of daily life, the interruption of medications for OA was not recommended. The WOMAC questionnaire was applied in order to verify the level of functional capacity of the knee, and the MEEM to assess the cognitive level.

For the application of the tests, the subjects wore a short pants and a T-shirt. In the case of long hair, it was advised to release them. The following tests, ordered by simple random selection:
1) Berg Balance Scale

Before the execution by the subjects, it was demonstrated and/or given the instructions on how to perform each task as described in the scale. In cases where supervision was required during the test, the examiner remained close to the subject or was allowed the use of external support. The subjects were oriented in order to maintain the balance as much as possible during the accomplishment of the tasks. For tasks, such as one-way support or anterior reach with the help of the upper limb, the choice of the executing member was at the discretion of the subject.

To perform this test was used a chronometer, a $200 \mathrm{~cm}$ tape measure, an object of $5 \mathrm{~cm}$ in height, a bench with a height of $15 \mathrm{~cm}$, a chair with support for upper limbs, approximately $42 \mathrm{~cm}$ high and with arms of $62 \mathrm{~cm}$ of height, and a chair without support for upper limbs of approximately $42 \mathrm{~cm}$ in height.

\section{2) Timed get up and to go test (TUG)}

The TUG test was performed using usual shoes. In the test, the subject starts from the initial position with his back resting on the chair, and is instructed to stand up, walk a linear course of 3 meters to a predetermined point marked on the floor, return and sit again supporting the back in the same chair, raising the lower limbs, straight. The subject was instructed not to talk during the execution of the test and perform it at a custom self-selected speed, safely. The test started after the starting signal shown simultaneously by the bending of the evaluator's left arm and by the verbal command "go" (the instant the timing starts). The timing was stopped only when the subject returned to the initial sitting position with his back resting on the chair after performing the trajectory in both directions. The time was recorded in seconds and noted on the patient record. An attempt was made to familiarize. Thereafter, three trials were performed and the mean number of trials was recorded.

3) Evaluation of the Near-Static Bipodal Balance

The Evaluation of the Near-Static Bipodal Balance was performed by the Chattecx Balance System ${ }^{\circledR}$. In the evaluation of the balance, the participants remained in rest and barefoot on the platform. They were advised to assume an orthostatic position with upper limbs along the body, parallel feet $10 \mathrm{~cm}$ apart, forward looking, straight head and without lateral inclination. The balance measurement on the platform was performed under two conditions: with eyes open and closed. In order to determine the order of the visual condition to be 
evaluated first the simple random model was adopted, by means of lottery. In the visual condition with open eyes, the evaluated ones focused on a circular area, with the diameter of five centimeters, at a distance of two meters ahead. And in the visual condition with closed eyes, they were instructed to focus on the circular area again and close their eyes for a new measurement. Data acquisition occurred for a period of 25 seconds and a frequency of $100 \mathrm{~Hz}$, with pre-filtering of $15 \mathrm{hz}$ determined by the platform. Three trials were performed for each visual condition, in an intercalated fashion, with a rest time of one minute between each procedure.

\section{Data analysis}

The data obtained in the cadastral record, socio demographic data, physical health, anthropometric data, fall history, WOMAC questionnaire, mental health status (MEEM), analog pain scale, image examination, TUG test run time, and Berg balance scale score (BBS) were recorded in Microsoft Excel software spreadsheet. The Matlab 6.5 Software was used to manage the data acquisition, storage and processing parameters of the Center of pressure (COP), in order to analyze the behavior of the COP diffusion stabilogram using the random walks routine established in this same program, developed by PhD Marcos Duarte from Universidade de São Paulo - USP, Brasil. Statistical treatment was used: asymmetry and kurtosis of the normality curve and descriptive statistics (mean, standard deviation, percentage, frequency); The Shapiro-Wilk test indicated that the variables had no normal distribution. The Mann Whitney $U$ test was used to compare the groups. All tests adopted the level of significance of $5 \%(\alpha=0.05)$. The SPSS 17.0 was used for the analysis.

\section{RESULTS}

Mean body mass and body mass index (BMI) showed a significant difference in the osteoarthritis groups $\left(\mathrm{KOA}_{\mathrm{F}}\right.$ and $\mathrm{KOA}_{\mathrm{NF}}$ ) in comparison with CG. (Table 1). Regarding health problems, subjects with $\mathrm{KOA}\left(\mathrm{KOA}_{\mathrm{F}}\right.$ and $\left.\mathrm{KOA}_{\mathrm{NF}}\right)$ reported a higher prevalence of disease than the subjects of the CG, with a significant difference only in diseases of the musculoskeletal system and/or connective tissue (Table 2). Data reinforced by the greater frequency in the use of drugs for the musculoskeletal system in OA groups than the control group ( $p<0.001$ for both). For the other clinical data, in the total sample, most of the subjects reported visual impairment (62.5\%, having a higher myopia report), absence of hearing loss (90.6\%) and dizziness (87.5\%), however, significant difference was observed between groups. In relation to the practice of regular physical activity, 13 participants of KOA and 15 participants of $\mathrm{KOA}_{\mathrm{NF}}$ did not practice physical activity regularly compared to the CG group, in which only three participants who did not practice $(p<0.001)$. The self-report
Table 1 - Group chronological and anthropometric data

\begin{tabular}{|c|c|c|c|c|}
\hline & \multicolumn{3}{|c|}{ Frequency $(s)$} & \multirow{2}{*}{$\rho$} \\
\hline & $K^{\prime} A_{F}$ & $\mathrm{KOA}_{\mathrm{NF}}$ & CG & \\
\hline Age (years) & $63.12( \pm 3.3)$ & $61.22( \pm 2.3)$ & $65.61( \pm 1.8)$ & ns \\
\hline Body mass (kg) & $80.45( \pm 3.2)$ & $83.13( \pm 3.3)$ & $65.47( \pm 2.9) * \Delta$ & $<0.001$ \\
\hline Height $(\mathrm{cm})$ & $157( \pm 0.02)$ & $162( \pm 0.02)$ & $150( \pm 0.08)$ & ns \\
\hline Body Mass Index & $32.61( \pm 1.14)$ & $31.41( \pm 1.26)$ & $26.24( \pm 1.01)^{* \boldsymbol{\Delta}}$ & 0.001 \\
\hline
\end{tabular}

Note: * significant difference between the KOA and CG ( $\rho<0.05) ; \boldsymbol{\Delta}$ significant difference between the KOA $A_{\mathrm{NF}}$ and $C G(\rho<0.05)$; ns: no significant difference

Table 2 - Health problem reported by groups

\begin{tabular}{|c|c|c|c|c|}
\hline & \multicolumn{3}{|c|}{ Frequency $(s)$} & \multirow{2}{*}{$\rho$} \\
\hline & $\mathrm{KOA}_{\mathrm{F}} \#$ & $\mathrm{KOA}_{\mathrm{NF}} \#$ & CG & \\
\hline Carriers of diseases & $17(94.4 \%)$ & $17(70.8 \%)$ & $14(63.6 \%)$ & 0.068 \\
\hline \multicolumn{5}{|l|}{ Health problems: } \\
\hline $\begin{array}{l}\text { Nutritional and/or } \\
\text { Metabolic Endocrine } \\
\text { Diseases }\end{array}$ & $7(38.9 \%)$ & $4(16.7 \%)$ & $3(13.6 \%)$ & 0.116 \\
\hline $\begin{array}{l}\text { Diseases of the } \\
\text { nervous system }\end{array}$ & $1(5.6 \%)$ & $3(12.5 \%)$ & $3(13.6 \%)$ & 0.684 \\
\hline $\begin{array}{l}\text { Diseases of the ear } \\
\text { and mastoid process }\end{array}$ & $3(16.7 \%)$ & $5(20.8 \%)$ & $2(9.1 \%)$ & 0.543 \\
\hline $\begin{array}{l}\text { Diseases of the } \\
\text { circulatory system }\end{array}$ & $10(55.6 \%)$ & $11(45.8 \%)$ & $8(36.4 \%)$ & 0.478 \\
\hline $\begin{array}{l}\text { Diseases of the } \\
\text { digestive system }\end{array}$ & $2(11.1 \%)$ & $2(8.3 \%)$ & $2(9.1 \%)$ & 0.953 \\
\hline $\begin{array}{l}\text { Skin and/or } \\
\text { subcutaneous tissue } \\
\text { disorders }\end{array}$ & $2(11.1 \%)$ & $2(8.3 \%)$ & 0 & 0.306 \\
\hline $\begin{array}{l}\text { Diseases of the } \\
\text { musculoskeletal } \\
\text { system and/or } \\
\text { connective tissue }\end{array}$ & $15(83.3 \%)^{*}$ & $16(66.7 \%)^{*}$ & $3(13.6 \%)$ & $<0.001$ \\
\hline $\begin{array}{l}\text { Diseases of the } \\
\text { genitourinary system }\end{array}$ & $2(11.1 \%)$ & $1(4.2 \%)$ & $1(4.5 \%)$ & 0.603 \\
\hline Drugs & $14(77.8 \%)$ & $18(75 \%)$ & $13(59.1 \%)$ & 0.357 \\
\hline \multicolumn{5}{|l|}{$\begin{array}{l}\text { Use of the medicinal } \\
\text { product for: }\end{array}$} \\
\hline $\begin{array}{l}\text { Food and/or } \\
\text { metabolic treatment }\end{array}$ & $7(38.9 \%)^{*}$ & $2(8.3 \%)$ & 2 (9.1\%) & 0.016 \\
\hline $\begin{array}{l}\text { Cardiovascular } \\
\text { system }\end{array}$ & $9(50 \%)$ & $14(58.3 \%)$ & $9(40.9 \%)$ & 0.498 \\
\hline $\begin{array}{l}\text { Muscle skeletal } \\
\text { system }\end{array}$ & $10(55.5 \%)^{*}$ & $10(41.7 \%)^{*}$ & 0 & 0.001 \\
\hline Nervous system & $2(11.1 \%)$ & $3(12.5 \%)$ & $3(13.6 \%)$ & 0.972 \\
\hline Systemic Hormones & 0 & $5(20.8 \%)$ & $5(22.7 \%)$ & 0.097 \\
\hline Sensory organ & $1(5.6 \%)$ & 0 & $1(4.5 \%)$ & 0.738 \\
\hline $\begin{array}{l}\text { Genitourinary system } \\
\text { and sex hormones }\end{array}$ & 0 & 0 & $1(4.5 \%)$ & 0.379 \\
\hline
\end{tabular}

Note: ${ }^{*}$ - significant difference in relation to the control group. \#excluded the Knee osteoarthritis. 
of fear of falling was present in $94.4 \%$ of the $\mathrm{KOA}_{\mathrm{F}}$ and $70.8 \%$ of the $\mathrm{KOA}_{\mathrm{NF}}$ versus $45,5 \%$ of the CG, evidencing a significant difference of $\rho=0.009$ (Table 2). The KOA reported a prevalence of $2.1( \pm 0.5)$ in the year, and $33.33 \%$ had a restriction of daily life activities after the fall.

All subjects with osteoarthritis of the knee joint reported an allergic complaint in the knee region on the day of collection, in the $\mathrm{KOA}_{\mathrm{F}}$ the average pain was $5.8( \pm 0.65)$ restricting their daily life activities in $77.8 \%$ of the subjects, while the average pain in the $\mathrm{KOA}_{\mathrm{NF}}$ was $5.7( \pm 0.42)$, with restriction of the their daily life activities in $70.8 \%$. The intensity of pain and restriction of the daily life activities showed no significant difference between the two groups, whereas among the volunteers of the CG there was no report of an allergic complaint. Regarding the degree of joint impairment, obtained by the Kellgren-Lawrence radiological graduation, $50 \%$ and $66.6 \%$ of subjects with $\mathrm{KOA}_{\mathrm{F}}$ presented degrees 3 and 4 in the right and left knee, respectively. In the $\mathrm{KOA}_{\mathrm{NF}}, 54.2 \%$ and $58.4 \%$ showed degrees 3 and 4 in the right and left knee, respectively. There was no significant difference between the two groups.

When assessing the functional capacity level of the knee joint, most subjects with osteoarthritis (KOAF $=55.6 \%$ and KOANF $=50 \%$ ) presented high and severe disability. However, there was a significant difference in the mean WOMAC score ( $p=0.001$ ) only in the comparison of CG with groups with osteoarthritis: $\mathrm{KOAF}=44.91( \pm 5.42), \mathrm{KOANF}=50.61( \pm 5.67)$ for the CG $=98.3( \pm 2.2)$.

\section{ANALYSIS OF DYNAMIC BALANCE}

In relation to the dynamic balance by timed TUG, the post hoc test Tukey showed that the $\operatorname{KOAF}(16.32 \pm 1.12 \mathrm{~s})$ was slower than KOANF $(13.07 \pm 0.91 \mathrm{~s})$ and the CG $(9.59 \pm 0.45 \mathrm{~s})$, showing significant difference of $\rho=0.027$ and $\rho<0.001$ between these groups, respectively. It was also found that the $\mathrm{KOA}_{\mathrm{NF}}$ was slower than the $C G$, showing significant difference $(\rho=0.011)$. In the evaluation of dynamic and static balance by EBB, the post hoc test Tukey showed that KOAF ( $46.7 \pm 1.0$ pontos) had lower score than KOANF ( $49.7 \pm 0.9$ pontos) and CG ( $54.2 \pm 0.4$ pontos), showing significant difference of $\rho=0.036$ and $\rho<0.001$ between these groups, respectively. It was also found that the KOANF had lower score than CG, showing significant difference of $\rho=0.001$.

\section{TRADITIONAL COP VARIABLES}

When comparing the COP variables in the open-eyes condition, there was a difference of the maximum displacement of the COP ap between the CG with KOAF and with KOANF $(\rho=0.03$ and $\rho<0.001$, respectively). However, there was no statistically significant difference between the KOA groups with fall and with no fall. In relation to the other variables of the traditional COP (COP ${ }_{\mathrm{m}} ; \mathrm{VEL}_{\mathrm{ap}} \mathrm{VEL}_{\mathrm{ml}}$, ellipse area), the results did not show significant differences between the groups. In the situation with closed eyes, the results showed that the $\mathrm{KOA}_{\mathrm{F}}$ and $\mathrm{KOA}_{\mathrm{NE}}$ respectively, had higher values of the maximum displacement of the $\operatorname{COP}_{a p}(p=0.03$ and $p<0.001)$, $V_{\text {Ep }}(p=0.03$ and $p=0.02)$ and ellipse area $(p=0.03$ and $p=0.05)$ than in the CG group. Besides this, the $\mathrm{KOA}_{\mathrm{F}}$ showed higher $\mathrm{VEL}_{\mathrm{ml}}$ than the CG $(\mathrm{p}=0.02)$ (Table 3$)$.

\section{BEHAVIOR OF DIFFUSION STABILOGRAM}

When analyzing the behavior of the mean curves of the anteroposterior (AP) diffusion stabilogram of the groups, in figure 1 , in the open and closed eyes conditions, the KOA and $\mathrm{KOA}_{\mathrm{NF}}$ presented higher mean curves than the CG. In the open-eyes situation, the KOA group with fall presented a

Table 3 - Comparison of the quasi-static balance variables in open and closed eyes

\begin{tabular}{|c|c|c|c|c|}
\hline Variables & Group & $\overline{\mathbf{X}}$ & $S$ & $\rho$ \\
\hline \multirow{3}{*}{$\mathrm{COP}_{\mathrm{AP}} \mathrm{OE}(\mathrm{mm})$} & $\mathrm{KOA}_{\mathrm{F}}^{*}$ & 2.6 & \pm 0.26 & \multirow{3}{*}{0.001} \\
\hline & $\mathrm{KOA}_{\mathrm{NF}}^{*}$ & 3.1 & \pm 0.32 & \\
\hline & CG & 1.6 & \pm 0.15 & \\
\hline \multirow{3}{*}{$\mathrm{COP}_{\mathrm{ml}} \mathrm{OE}(\mathrm{mm})$} & $\mathrm{KOA}_{F}$ & 3.2 & \pm 0.5 & \multirow{3}{*}{0.072} \\
\hline & $\mathrm{KOA}_{\mathrm{NF}}$ & 3.1 & \pm 0.5 & \\
\hline & CG & 1.8 & \pm 0.3 & \\
\hline \multirow{3}{*}{$\mathrm{VEL}_{\mathrm{ap}} \mathrm{OE}\left(\mathrm{mm} / \mathrm{s}^{2}\right)$} & $\mathrm{KOA}_{\mathrm{F}}$ & 17.2 & \pm 2.2 & \multirow{3}{*}{0.085} \\
\hline & $\mathrm{KOA}_{\mathrm{NF}}$ & 16.0 & \pm 1.3 & \\
\hline & CG & 12.1 & \pm 1.5 & \\
\hline \multirow{3}{*}{$V_{E L_{m l}} O E\left(m m / s^{2}\right)$} & $\mathrm{KOA}_{\mathrm{F}}$ & 13.6 & \pm 2.1 & \multirow{3}{*}{0.204} \\
\hline & $\mathrm{KOA}_{\mathrm{NF}}$ & 12.6 & \pm 1.8 & \\
\hline & CG & 9.4 & \pm 1.2 & \\
\hline \multirow{3}{*}{$\begin{array}{l}\text { Ellipse area OE } \\
\left(\mathrm{cm}^{2}\right)\end{array}$} & $\mathrm{KOA}_{\mathrm{F}}$ & 0.93 & \pm 0.1 & \multirow{3}{*}{0.163} \\
\hline & $\mathrm{KOA}_{\mathrm{NF}}$ & 0.98 & \pm 0.2 & \\
\hline & CG & 0.66 & \pm 0.7 & \\
\hline \multirow{3}{*}{$\mathrm{COP}_{\mathrm{ap}} \mathrm{CE}(\mathrm{mm})$} & $\mathrm{KOA}_{\mathrm{F}}{ }^{*}$ & 1.9 & \pm 0.28 & \multirow{3}{*}{$<0.001$} \\
\hline & $\mathrm{KOA}_{\mathrm{NF}}{ }^{*}$ & 2.4 & \pm 0.24 & \\
\hline & CG & 1.1 & \pm 0.13 & \\
\hline \multirow{3}{*}{$\mathrm{COP}_{\mathrm{ml}} \mathrm{CE}(\mathrm{mm})$} & $\mathrm{KOA}_{\mathrm{F}}$ & 2.9 & \pm 0.4 & \multirow{3}{*}{0.265} \\
\hline & $\mathrm{KOA}_{\mathrm{NF}}$ & 3.3 & \pm 0.6 & \\
\hline & CG & 2.1 & \pm 0.3 & \\
\hline \multirow{3}{*}{$\mathrm{VEL}_{\mathrm{AP}} \mathrm{CE}\left(\mathrm{mm} / \mathrm{s}^{2}\right)$} & $\mathrm{KOA}_{\mathrm{F}}^{*}$ & 20.0 & \pm 2.1 & \multirow{3}{*}{0.009} \\
\hline & $\mathrm{KOA}_{\mathrm{NF}}^{*}$ & 20.0 & \pm 1.7 & \\
\hline & CG & 13.0 & \pm 1.7 & \\
\hline \multirow{3}{*}{$\mathrm{VEL}_{\mathrm{ml}} \mathrm{CE}\left(\mathrm{mm} / \mathrm{s}^{2}\right)$} & $\mathrm{KOA}_{\mathrm{F}}{ }^{*}$ & 14.6 & \pm 1.6 & \multirow{3}{*}{0.023} \\
\hline & $\mathrm{KOA}_{\mathrm{NF}}$ & 12.4 & \pm 1.2 & \\
\hline & CG & 9.2 & \pm 1.1 & \\
\hline \multirow{3}{*}{$\begin{array}{l}\text { Ellipse area CE } \\
\left(\mathrm{cm}^{2}\right)\end{array}$} & $\mathrm{KOA}_{\mathrm{F}}^{*}$ & 1.05 & \pm 0.12 & \multirow{3}{*}{0.019} \\
\hline & $\mathrm{KOA}_{\mathrm{NF}}{ }^{*}$ & 1.00 & \pm 0.08 & \\
\hline & CG & 0.69 & \pm 0.08 & \\
\hline
\end{tabular}

Note: OE - open eyes, CE - closed eyes; $\rho$ - level of significance of the ANOVA one-way test. * significant difference between the KOA with fall and Control of $p<0.05$. 

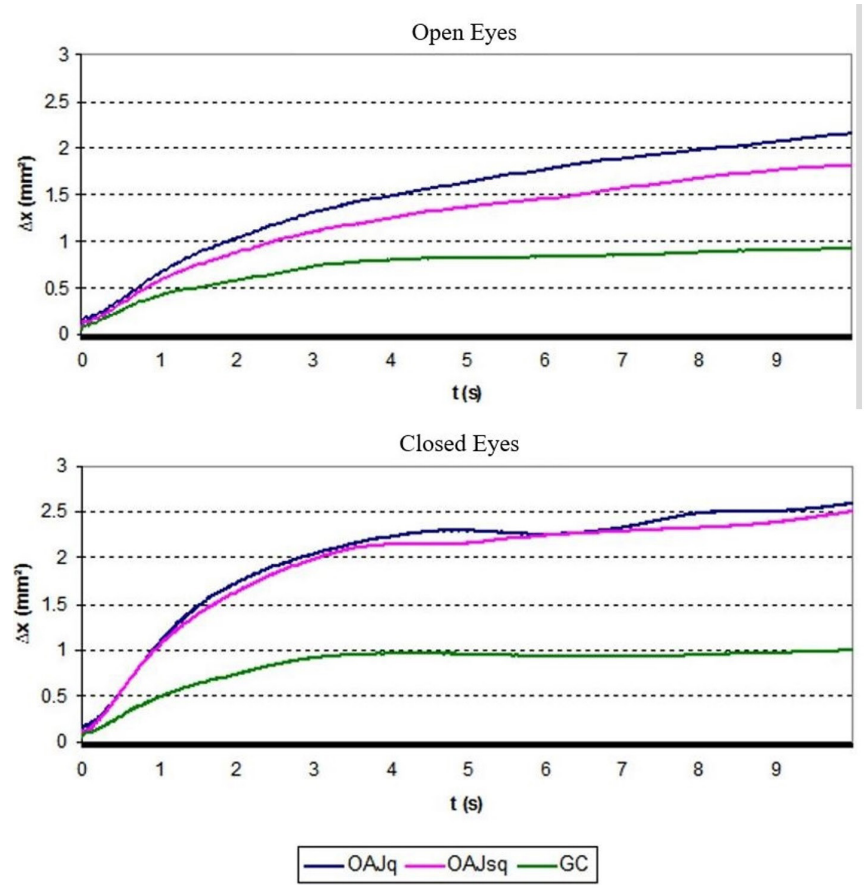

Figure 1 - Mean curve of the diffusion stabilogram in the antero posterior direction in the two visual conditions. Note: OAJq: Knee Osteoarthritis Group with Fall History group; OAJsq: Knee Osteoarthritis Group with No Fall History; CG: control group

mean curve higher than the group with no fall. However, in the non-visual stimulus situation, subjects with KOA with and without fall had similar mean curves (Figure 1). Thus, when analyzing the mean values of the diffusion coefficient in the region of short time interval (DST), long time interval (DLT) and critical point position $\left(\Delta x^{2}\right)$, it can be observed that the mean values were higher in subjects with osteoarthritis $\left(\mathrm{KOA}_{\mathrm{F}}\right.$ and $\mathrm{KOA}_{\mathrm{NF}}$ ) in relation to $C G$, presenting a statistically significant difference in both visual conditions, in these variables (Table 4).

When evaluating the behavior of the medium-lateral diffusion stabilogram (ML) curves of the groups, in Figure 2, in the open and closed eyes conditions, subjects with KOA presented mean curves higher than CG. However, under both conditions it is noted that the $\mathrm{KOA}_{\mathrm{NF}}$ had its mean curve of the stabilogram very close to the $\mathrm{KOA}_{\mathrm{F}}$. In the situation with closed eyes, the CG presented a curve very close to the KOA groups. In this way, ML variables in both conditions did not present a statistically significant difference.

\section{DISCUSSION}

The KOAF and KOANF had higher BMI than $30 \mathrm{Kg} / \mathrm{m}^{2}$ showing tendency to be overweight and obese. This result is in line with epidemiological studies that have consistently shown the increased prevalence of KOA directly associated with increased $\mathrm{BM} \mathrm{I}^{(7,8)}$. Several studies have demonstrated a significant relationship between obesity and functional disability ${ }^{(7,8)}$. This association is reinforced by a reverse
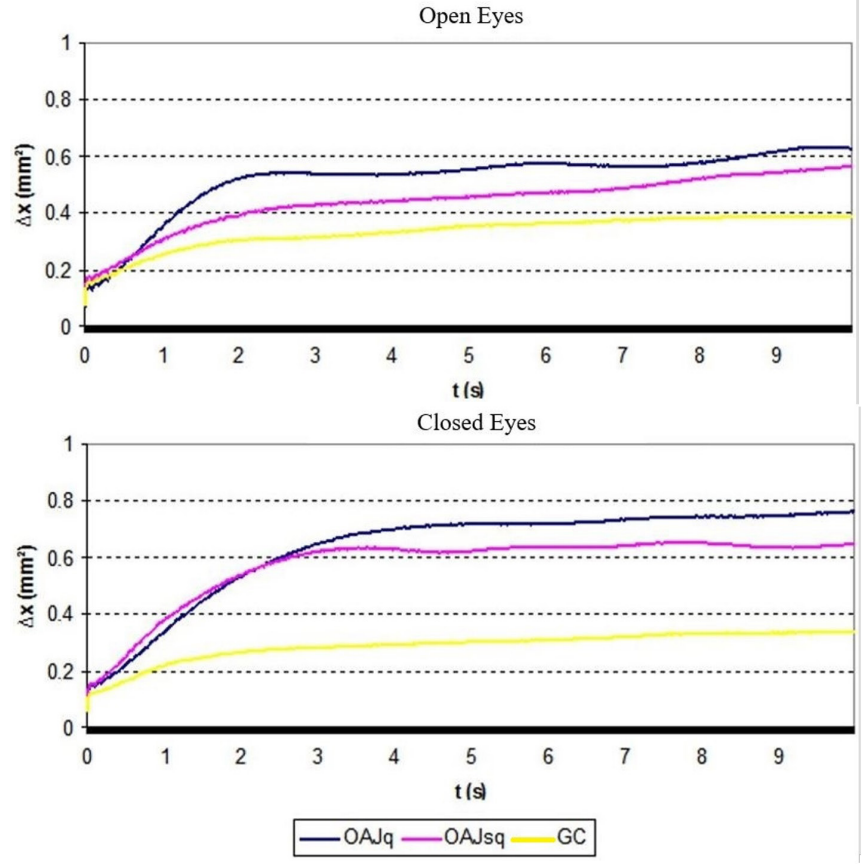

Figure 2 - Mean curve of diffusion stabilogram medium-lateral direction in both visual conditions. Note: OAJq: Knee Osteoarthritis Group with Fall History group; OAJsq: Knee Osteoarthritis Group with No Fall History; GC: control group.

causality, since subjects with KOA tend to be more inactive and therefore have a higher $\mathrm{BMI}^{(7,8)}$. Thus, when investigating the prevalence of physical activity among the groups of this study, it was verified that the majority of KOA patients were not regular physical activity practitioners, while in the CG they practiced physical activity more than three times a week. These results indicate that KOA patients are more prone to physical inactivity than non-carriers, and may favor the tendency for obesity in this population. Radominski $\mathrm{i}^{(9)}$, through $\mathrm{BMI}$ and cutaneous folds, reported that joint pain is a very frequent and aggravating symptom in overweight subjects, as it causes mechanical overload to bones and joints. Thus, overweight has an important role in the pathogenesis, clinical manifestations and evolution of musculoskeletal diseases, explaining the higher prevalence of these in subjects with KOA compared to CG. Consequently, it was noted a higher prevalence of the use of anti-inflammatory drugs, analgesics and muscle relaxants.

In the current literature, studies ${ }^{(10,11)}$ considered as risk factors for falls and functional dependence: reporting chronic diseases, medication use, reports of previous fractures, vision problems, hearing problems, dizziness and fear of falling. Regarding vision, hearing and dizziness, there was no statistical difference between the groups. However, KOA patients were more concerned about falling, perhaps due to impaired functional capacity. Fear leads to insecurity, dependence on activities of daily living, restriction in social activities and consequent decrease of autonomy over 
Table 4 - Comparison of diffusion stabilogram parameters in anteroposterior direction with open and closed eyes.

\begin{tabular}{|c|c|c|c|c|}
\hline VARIABLE & GROUPS & $\overline{\mathbf{X}}$ & $\mathbf{S}$ & $\rho$ \\
\hline \multirow{3}{*}{ DLT AP OE $\left(\mathrm{mm}^{2} / \mathrm{s}\right)$} & $\mathrm{KOA}_{\mathrm{F}}$ & 0.09 & 0.04 & \multirow{3}{*}{0.003} \\
\hline & $\mathrm{KOA}_{\mathrm{NF}}$ & 0.09 & 0.02 & \\
\hline & $\mathrm{CG}^{\ddagger \boldsymbol{\Delta}}$ & 0.02 & 0.01 & \\
\hline \multirow{3}{*}{ DST AP OE $\left(\mathrm{mm}^{2} / \mathrm{s}\right)$} & $\mathrm{KOA}_{\mathrm{F}}$ & 0.31 & 0.08 & \multirow{3}{*}{0.006} \\
\hline & $\mathrm{KOA}_{\mathrm{NF}}$ & 0.29 & 0.04 & \\
\hline & $\mathrm{CG}^{\ddagger \boldsymbol{\Delta}}$ & 0.19 & 0.08 & \\
\hline \multirow{3}{*}{ HLT AP OE (adc) } & $\mathrm{KOA}_{\mathrm{F}}$ & 0.25 & 0.03 & \multirow{3}{*}{0.987} \\
\hline & $\mathrm{KOA}_{\mathrm{NF}}$ & 0.27 & 0.03 & \\
\hline & CG & 0.25 & 0.03 & \\
\hline \multirow{3}{*}{ HST OE AP } & $\mathrm{KOA}_{\mathrm{F}}$ & 0.26 & 0.04 & \multirow{3}{*}{0.396} \\
\hline & $\mathrm{KOA}_{\mathrm{NF}}$ & 0.26 & 0.04 & \\
\hline & CG & 0.31 & 0.03 & \\
\hline \multirow{3}{*}{$\Delta \mathrm{x}^{2} \mathrm{AP} O \mathrm{OE}\left(\mathrm{mm}^{2}\right)$} & $\mathrm{KOA}_{\mathrm{F}}$ & 0.51 & 0.10 & \multirow{3}{*}{0.004} \\
\hline & $\mathrm{KOA}_{\mathrm{NF}}$ & 0.51 & 0.08 & \\
\hline & $\mathrm{CG}^{ \pm \boldsymbol{\Lambda}}$ & 0.25 & 0.08 & \\
\hline \multirow{3}{*}{$\Delta r^{2} c$ AP OE (s) } & $\mathrm{KOA}_{F}$ & 0.94 & 0.19 & \multirow{3}{*}{0.658} \\
\hline & $\mathrm{KOA}_{\mathrm{NF}}$ & 0.83 & 0.12 & \\
\hline & CG & 0.92 & 0.14 & \\
\hline \multirow{3}{*}{ DLT AP CE $\left(\mathrm{mm}^{2} / \mathrm{s}\right)$} & $\mathrm{KOA}_{F}$ & 0.07 & \pm 0.03 & \multirow{3}{*}{0.001} \\
\hline & $\mathrm{KOA}_{\mathrm{NF}}$ & 0.08 & 0.02 & \\
\hline & $\mathrm{CG}^{\ddagger \boldsymbol{\Delta}}$ & 0.01 & \pm 0.01 & \\
\hline \multirow{3}{*}{ DST AP CE $\left(\mathrm{mm}^{2} / \mathrm{s}\right)$} & $\mathrm{KOA}_{\mathrm{F}}$ & 0.48 & \pm 0.13 & \multirow{3}{*}{0.004} \\
\hline & $\mathrm{KOA}_{\mathrm{NF}}$ & 0.59 & \pm 0.01 & \\
\hline & $\mathrm{CG}^{\ddagger \boldsymbol{\Delta}}$ & 0.22 & \pm 0.06 & \\
\hline \multirow{3}{*}{ HLT AP CE } & $\mathrm{KOA}_{\mathrm{F}}$ & 0.16 & \pm 0.02 & \multirow{3}{*}{0.664} \\
\hline & $\mathrm{KOA}_{\mathrm{NF}}$ & 0.19 & \pm 0.02 & \\
\hline & CG & 0.18 & \pm 0.03 & \\
\hline \multirow{3}{*}{ HST AP CE } & $\mathrm{KOA}_{\mathrm{F}}$ & 0.33 & \pm 0.04 & \multirow{3}{*}{0.693} \\
\hline & $\mathrm{KOA}_{\mathrm{NF}}$ & 0.33 & \pm 0.03 & \\
\hline & CG & 0.36 & \pm 0.03 & \\
\hline \multirow{3}{*}{$\Delta \mathrm{x}^{2} \mathrm{AP} C E\left(\mathrm{~mm}^{2}\right)$} & $\mathrm{KOA}_{\mathrm{F}}$ & 1.30 & \pm 0.52 & \multirow{3}{*}{0.007} \\
\hline & $\mathrm{KOA}_{\mathrm{NF}}$ & 1.03 & \pm 0.02 & \\
\hline & $\mathrm{CG}^{\ddagger \boldsymbol{\Lambda}}$ & 0.44 & \pm 0.16 & \\
\hline \multirow{3}{*}{$\Delta r^{2} c$ AP CE (s) } & $\mathrm{KOA}_{F}$ & 0.84 & \pm 0.16 & \multirow{3}{*}{0.908} \\
\hline & $\mathrm{KOA}_{\mathrm{NF}}$ & 0.96 & \pm 0.17 & \\
\hline & CG & 0.86 & \pm 0.13 & \\
\hline
\end{tabular}

Note: KOA - knee osteoarthritis; OE - open eyes, CE - closed eyes, DST - short time interval; DLT- long time interval; HLT - exponent of Hurst long interval of time; HST - exponent of Hurst short interval of time; $\Delta \mathrm{x}^{2}$ Critical point position; $\Delta \mathrm{r}^{2} \mathrm{c}-$ instant of critical point, $\rho$ - level of significance of ANOVA one-way test. $¥$ significant difference between the KOA with fall and control $(\rho<0.05) ; \boldsymbol{\Delta}$ significant difference between the KOA with no fall and control $(\rho<0.05)$;

time. The results of this study showed no difference in pain intensity on the day of collection between subjects from the KOAF and KOANF group. Pain and joint spillage can lead to motor unit inhibition. This mechanism, known as "reflex inhibition" prevents the muscle from producing maximum force and decreases the speed of contraction, contributing to muscle weakness, especially observed in the quadriceps of patients with $O A^{(11,12)}$. Consequently, results from the WOMAC questionnaire showed that most subjects with KOA had a level of high or severe disability. The maintenance of functional capacity is a fundamental requirement for healthy aging and may have important implications for the quality of life of these subjects ${ }^{(7,8)}$.

Regarding the analysis of the dynamic balance, the results showed that subjects with KOAF were more likely to fall than KOANF and CG subjects. This finding is in line with a number of previous studies, which have shown that the elderly who suffered falls have a significantly lower functional performance in BBS and TUG than in the elderly without reports of falls ${ }^{(13,14,15)}$. The result of this study was congruent with the Sun et al. ${ }^{(16)}$, which also showed that the subjects with KOA had lower performance in the EBB and TUG than the subjects without KOA.

Studies have shown that muscle weakness of the lower limbs (mainly the quadriceps), reduced activation of muscle fiber numbers, increased latency of recruitment of muscle fibers, and proprioceptive deficit of the knee joint are the primary causes for imbalance of these subjects ${ }^{(17)}$. Since these circumstances significantly affect the performance of neuromuscular coordination automatically, maintaining balance in the orthostatic position will be impaired ${ }^{(18)}$. In this context, studies as Perracini and Ramos ${ }^{(19)}$ showed a strong association between functional status and the presence of falls, suggesting that the impairment of functional capacity seems to play a preponderant role in the multicausal interaction of falls.

Regarding the variables of the traditional COP, the results of this study did not indicate a significant difference in the COP stabilogram variables between the KOAF and KOANF, which can be explained by the homogeneity of the clinical picture The same finding was found by Petrella et al. ${ }^{(20)}$, in which showed no difference between groups of osteoarthritis with and without a history of falls, but rather between carriers and non-osteoarthritis patients. The authors concluded that the disease factor was predominant to change the COP in the AP direction, presenting greater displacement compared to the group without $O A$, regardless of the history of fall. Some authors ${ }^{(21,22)}$ found greater COP displacement in both directions in subjects with KOA suggesting that this population presents alterations in postural balance. The same authors showed that subjects with greater COP displacement are more susceptible to falls than those with lower COP variation in quasi-static posture.

Subjects with KOA tend to have a higher velocity of postural oscillation and greater area of the COP ellipse than healthy subjects, which indicates a worsening of their postural balance. Being that they presented higher mean velocity of the 
anteroposterior COP (VELAP) and the area of the COP ellipse independent of the visual condition, and the mean velocity of the mid-lateral COP (VELML) in the closed eyes condition, compared to the CG. In current literature, only MASUI et al. ${ }^{\text {(23) }}$ analyzed the COP velocity in subjects with KOA, detecting that men presented a higher mean total COP in closed eyes, and women, in both visual conditions. Himann et al. ${ }^{(24)}$ reported that KOA patients had greater ellipse area, only in the openeye condition.

Postural stability requires adequate integration of peripheral, vestibular and visual sensory systems, as well as adequate motor control response to maintain balance ${ }^{(14)}$. Previous study ${ }^{(25)}$ reports that deficits in this system can alter the balance of the elderly, impairing their mobility and performance during the performance of their daily life activities, leading to a decrease in their functional independence. However, balance studies in subjects with KOA have yet to establish the relationship between these factors.

When was observed the behavior of the diffusion stabilogram curve, the results of this study showed that KOA patients presented higher mean diffusion stabilogram curves compared to CG subjects in both directions and conditions, in agreement with the studies of Mitchell et al. ${ }^{(26)}$ and Raymakers et al. (27). Thus, subjects with KOA of this study, regardless of the fall report, present larger curves of the diffusion stabilogram than healthy subjects, suggesting an increased risk of falling in this population.

In this study, the volunteers with KOA had higher values in DST and DLT than volunteers in the asymptomatic group, evidencing a deficit in sensory detection and in proprioceptive feedback that negatively affected body balance. The increase in AP activity in subjects with KOA could reflect an attempt to maintain the movements of the potentially stable $\mathrm{ML}$ direction. The subjects with OA use displacements and adjustments in the AP direction, through two mechanisms of postural control, open-loop and close-loop, as a compensatory strategy that aims to neutralize the effects of the restricted movements in the ML direction ${ }^{(26)}$. Some authors ${ }^{(6,26)}$, propose that the short-time region (DST) corresponds to the open circuit mechanism that does not allow direct control by the central nervous system. DThus, postural stability is only dependent on muscle tension (stiffness) ${ }^{(2,3)}$. Such alterations may occur in subjects in a condition of decreased muscle strength (coactivation) or with a decline in nerve conduction velocity, both of which are present in KOA physiology ${ }^{(28)}$. The volunteers with KOA presented higher DLT when compared to those without KOA. The DLT region corresponds to the closed circuit mechanism, which uses sensory information to generate corrective muscle torques to compensate for postural disorders ${ }^{(6)}$. Common consequences of the aging process and the pathophysiology of KOA, increased reflex time, decreased proprioception, and muscle weakness justify the delay in the activation of closed loop feedback mechanisms ${ }^{(28)}$.
Regarding the history of fall, this study did not find a significant difference in DST and DLT among KOA subjects with and without a history of falls, and can be explained by the homogeneity of the clinical picture between the groups. Therefore, regardless of the history of fall, both KOA groups have deficits in sensory detection and proprioceptive feedback, contributing to increased risk of falls. Raymakers et al. ${ }^{(27)}$ report that DST may be a better predictor of risk of falling than any other parameter, suggesting that proprioception of the lower limbs is particularly essential for maintaining the balance of KOA. In this study, KOA patients presented higher DST values. Laughton et al. ${ }^{(29)}$ concluded that increased muscle activity may be responsible for increased of the stochastic DST activity by compromising the individual's ability to maintain postural stability and increased risk of falls. KOA sufferers have deficits in the proprioception of the knee joint, lower limb muscle weakness (mainly the quadriceps), reduced number of muscle fiber activation, increased muscle recruitment latency time, and a deficit in the dynamic fit of muscle stiffness by means of muscle co-activation for joint stability control of the knee ${ }^{(17,18)}$. These factors may reflect on the DST and DLT parameters. Thus, increasing the risk of falling in this population by increasing the stochastic activity of COP, delayed sensory detection and responses of adequate postural control to stabilize postural oscillation. These circumstances associated with the aging process may negatively affect the confidence of subjects with KOA in performing daily life activities, rendering them more inactive and further hampering the motor control mechanisms of stabilizing body balance, further enhancing the risk to fall.

Regarding the intermediation phase between the short and long-term interval, this study found a significant difference in the value of $\Delta x^{2}$ between the subjects with KOA (KOA ${ }_{F}$ and $\mathrm{KOA}_{\mathrm{NF}}$ ) and asymptomatic subjects. The same was evidenced by Tanaka et al. ${ }^{\left({ }^{30}\right)}$, which the values of $\Delta x^{2}$ were higher in young adults with worse ability to maintain unipodal balance, suggesting that the high-risk group used a larger area of their support base faster than the low-risk group. However, this study did not show difference of the instant of the critical point $\Delta r^{2} c$ between the subjects with KOA (KOA $F_{F}$ and $K_{N F}$ ) and healthy subjects.

\section{CONCLUSION}

In the analysis of the diffusion stabilogram and traditional posturography, the results indicated that, regardless of the history of fall, subjects with KOA had a deficit of the equilibrium with a tendency to fall. The curve of the diffusion stabilogram of COP, subjects with $\mathrm{KOA}_{\mathrm{F}}$ and $\mathrm{KOA}_{\mathrm{NF}}$ presented similar curves, and the curves were superior to those of the asymptomatic subjects, in both directions and visual conditions. When comparing the diffusion stabilogram variables between the groups, KOA (KOAF and KOANF), both in open and closed eyes, presented higher values of the diffusion coefficient in the short time interval (DST), long time interval 
(DLT) and critical point position $\left(\Delta x^{2}\right)$, in the AP direction, than asymptomatic subjects. In this way, the KOA groups need a longer period for the sensorial detection, to execute the processing of the neural, sensorial transmission and muscular activation. The subjects with KOA presented higher stochastic activity of COP, evidenced through $\Delta \mathrm{x}^{2}$. Thus, in order to acquire postural stability, KOA patients took longer to stabilize postural control, used a larger area of their support base, and a greater velocity in COP displacement than those in the control group.

In the traditional posturography analysis, during the quasi-static equilibrium analysis, the KOA groups presented higher displacement and mean velocity of $\mathrm{COP}_{\mathrm{AP}}$, in both visual conditions, and greater area of the COP ellipse, in the condition of closed eyes, than the subjects of the control group. In addition, the results showed that KOA subjects presented greater displacement and velocity of the $\mathrm{COP}_{\mathrm{ap}}$ and ellipse area of the COP, being more susceptible to falls than those with lower COP variation in quasi-static posture.

\section{AUTHOR'S CONTRIBUTION}

ACSSM and GMS performed the data collection; GMSperformed the statistical analysis; ACSSM: writing of the article; GMS: Correction of the manuscript. All authors read and approved the final manuscript.

\section{CONFLICTS OF INTEREST}

The authors declare that there was no conflict of interests.

\section{AUTHOR DETAILS}

2 Physical Education Department, Universidade do Estado de Santa Catarina UDESC, Florianópolis (SC), Brazil.

\section{REFERENCES}

1. Salvato KF, Santos JPM, Pires-Oliveira DAA, Costa VSP. Análise da influência da farmacoterapia sobre a qualidade de vida em idosos com osteoartrite. Rev Bras Reumatol. 2015;55(1):83-8

2. Zeni JA, Higginson JS. Knee osteoarthritis affects the distribution of joint moments during gait. Knee. 2010;18:156-9.

3. Kim I, Kim HA, Seo YI, Song YW, Jeong JY, Kim DH. The prevalence of knee osteoarthritis in elderly community residents in Korea. J Korean Med Sci. 2010;25:293-8.

4. Alencar MA, Arantes PMM, Dias JMD, Kirkwood RN, Pereira LSM, Dias RC. Muscular function and functional mobility of faller and non-faller elderly women with osteoarthritis of the knee. Braz J Med Biol Res. 2007;40:27783.

5. Hamill J, Knutzen KM. Bases Biomecânicas do Movimento Humano. 3rd ed. São Paulo: Manole; 2012.

6. Collins JJ, De Luca CJ. Open loop and closed-loop control of posture: a random-walk analysis of center of pressure trajectories. Exp Brain Res.1993;95:308-13.

7. Colbert CJ, Song J, Dunlop D, Chmiel JS, Hayes KW, Cahue S, et al. Knee confidence as it relates to physical function outcome in persons with or at higher risk for knee osteoarthritis in the osteoarthritis initiative. Arthritis Rheum. 2012;64:1437-46.

8. Dunlop DD, Song J, Semanik PA, Sharma L, Chang RW. Physical activity levels and functional performance in the Osteoarthritis Initiative: a graded relationship. Arthritis Rheum. 2011;63:127-36.

9. Radominski, SC. Obesidade e doenças músculo-esqueléticas. Rev Bras Reumatol. 1998:38:275-8.
10. Reyes-Ortiz CA, Snih SA, Markides KS. Falls among elderly persons in Latin América and the Caribbean and among elderly Mexican-Americans. Rev Panam Salud Publica. 2005;17:362-9.

11. Santos KA, Koszuoski R, Costa JSD, Pattussi MP. Fatores associados com a incapacidade funcional em idosos do município de Guatambu Santa Catarina Brasil. Cad Saúde Pública. 2007;23:2781-8.

12. McNair PJ, Marshall RN, Maguire K. Swelling of the nee Joint: Effects of exercise on quadriceps muscle strength. Arch Phys Med Rehabil. 1996;77:896-

13. Mackintosh SF, Hill KD, Dodd KJ, Goldie PA, Culham EG. Balance score and a history of falls in hospital predict recurrent falls in the 6 months following stroke rehabilitation. Arch Phys Med Rehabil. 2006;87:1583-9.

14. Shumway-Cook A, Brauer S, Woollacott M. Predicting the probability for falls in community-dwelling older adults using the timed up and go test. Phys Ther. 2000;80:896-903.

15. Lajoie Y, Gallagher SP. Predicting falls within the elderly community: comparison of postural sway reaction time the Berg balance scale and the Activities-specific Balance Confidence $(A B C)$ scale for comparing fallers and non-fallers. Arch Gerontol Geriatr. 2004;38:11-26.

16. Sun SF, Hsu CW, Hwang CW, Hsu PT, Wang JL, Tsai SL, et al. Hyaluronate improves pain, physical function and balance in the geriatric osteoarthritic knee: a 6-month follow-up study using clinical tests. Osteoarthritis Cartilage. 2006;14(7):696-01.

17. Sharma L, Pai YC. Impaired proprioception and osteoarthritis. Curr Opin Rheumatol. 1997;9:253-8.

18. Ellenbecker TS. Reabilitação dos ligamentos do joelho. São Paulo: Manole; 2002

19. Perracini MR, Ramos LR. Fatores associados a quedas em uma coorte de idosos residentes na comunidade. Rev Saúde Pública. 2002;36:709-16.

20. Petrella M, Neves TM, Reis JG, Gomes MM, Oliveira RDR, Abreu DCC. Postural control parameters in elderly female fallers and non-fallers diagnosed or not with knee osteoarthritis. Rev Bras Reumatol. 2012;52:51217.

21. Haibach PS, Slobounov SM, Newell KM. The potential applications of a virtual moving environment for assessing falls in elderly adults. Gait Posture. 2008;27:303-8.

22. Ostrowska B, Kuczyński M, Dean E. Does osteoarthritis further compromise the postural stability of women with osteoporosis? Ortop Traumatol Rehabil. 2008;10:179-82

23. Masui T, Hasegawa Y, Yamaguchi J, Kanoh T, Ishiguro N, Suzuki S. Increasing postural sway in rural-community-dwelling elderly persons with knee osteoarthritis. J Orthop Sci. 2006;11(4):353-58.

24. Hinman RS, Bennell KL, Metcalf BR, Crossley KM. Balance impairments in subjects with symptomatic knee osteoarthritis: a comparison with matched controls using clinical tests. Rheumatology. 2002;41:1388-94.

25. Anson E, Bigelow RT, Swenor B, Deshpande N, Studenski S, Jeka JJ, et al. Loss of Peripheral Sensory Function Explains Much of the Increase in Postural Sway in Healthy Older Adults. Front Aging Neurosci. 2017;20(9):202.

26. Mitchell SL, Collins JJ, De Luca CJ, Burrows A, Lipsitz LA. Open-loop and closed-loop postural control mechanisms in Parkinson's disease: increased mediolateral activity during quiet standing. Neurosci Lett. 1995;197:133-6.

27. Raymakers JA, Samson MM, Verhaar HJJ. The assessment of body sway and the choice of the stability parameter(s). Gait Posture. 2005;21:48-58.

28. Kurz I, Oddsson L, Melzer I. Characteristics of balance control in older persons who fall with injury - A prospective study. J Electromyo Kinesio. 2013;23:814-9.

29. Laughton CA, Slavin M, Katdare K, Nolan L, Bean JF, Kerrigan DC, Phillips E, Lipsitz LA, Collins JJ. Aging muscle activity and balance control: physiologic changes associated with balance impairment. Gait Posture. 2003;18:101-8.

30. Tanaka H, Uetake T, Kuriki S, Ikeda S. Changes in centro-pressure dynamics during upright standing related to decreased balance control in young adults: fractional Brownian motion analysis. J Hum Ergol. 2002;31:1-11. 